\title{
Hydrogels for Two-Photon Polymerization: A Toolbox for Mimicking the Extracellular Matrix
}

\author{
Jan Torgersen, * Xiao-Hua Qin, Zhiquan Li, Aleksandr Ovsianikov, Robert Liska,* \\ and Jürgen Stampfl*
}

The natural extracellular matrix (ECM) represents a complex and dynamic environment. It provides numerous spatio-temporal signals mediating many cellular functions including morphogenesis, adhesion, proliferation and differentiation. The cell-ECM interaction is bidirectional. Cells dynamically receive and process information from the ECM and remodel it at the same time. Theses complex interactions are still not fully understood. For better understanding, it is indispensable to deconstruct the ECM up to the point of investigating isolated characteristics and cell responses to physical, chemical and topographical cues. Two-photon polymerization (2PP) allows the exact reconstruction of cell specific sites in 3D at micro- and nanometer precision. Processing biocompatible synthetic and naturally-derived hydrogels, the microenvironment of cells can be designed to specifically investigate their behavior in respect to key chemical, mechanical and topographical attributes. Moreover, 3D manipulation can be performed in the presence of cells, guiding biological tissue formation in all stages of its development. Here, advances in 2PP microfabrication of synthetic and naturally based hydrogels are reviewed. Key components of photopolymerizable hydrogel precursors, their structure-property relationships and their polymerization mechanisms are presented. Furthermore, it is shown how biocompatible 2PP fabricated constructs can act as biologically relevant matrices to study cell functions and tissue development. morphogenesis, provides cues for cell proliferation and differentiation, promotes the maintenance of differentiated tissues and enhances the repair response after injury. ${ }^{[2]}$ It serves as a reservoir for signaling molecules and 3D substructures for cell adhesion and proliferation. For tissue engineering, researchers have focused on mimicking key characteristics of the ECM to study cell responses to different mechanical, chemical and topographical cues. The composition of the natural ECMs was considered in the design of artificial biomaterial constructs. ${ }^{[3]}$

As different tissues require different ECM composition and physical properties, a rational design of artificial cell environments requires various considerations. Appropriate cell support for colonization, migration, growth and differentiation has to be ensured. Furthermore, the construct must have the necessary physiochemical properties, an adequate morphology and ensure proper degradation kinetics. ${ }^{[4]}$ FDA approved biomaterials are based on poly lactic acid, polycaprolactone, or poly(lactid-co-glycolide) providing good mechanical properties and controlled

\section{Introduction}

In human tissues, most cells are embedded within an intricate meshwork of interacting collagens, proteoglycans and adhesion proteins. ${ }^{[1]}$ They receive numerous signals from their natural surroundings, the extracellular matrix (ECM), which influence their behavior. The ECM functions as a scaffold for tissue

\footnotetext{
J. Torgersen, Dr. A. Ovsianikov, Prof. J. Stampfl Vienna University of Technology Institute of Materials Science and Engineering Favoritenstrasse 9-11, 1040 Vienna, Austria E-mail: jan.torgersen@tuwien.ac.at; juergen.stampfl@tuwien.ac.at

X.-H. Qin, Z. Li, Prof. R. Liska

Vienna University of Technology

Institute for Applied Synthetic Chemistry

Getreidemarkt 9, 1060 Vienna, Austria

E-mail: robert.liska@tuwien.ac.at
}

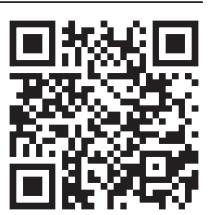

DOI: $10.1002 / \mathrm{adfm} .201203880$ degradation behavior. ${ }^{[3]}$ Although these materials have advantages related to their mechanics, they are rather stiff and hydrophobic and do not provide the ideal environment for cell-ECM interactions. ${ }^{[5,6]}$

Being structurally similar to the ECM, hydrogels are an appealing material for various biomedical applications such as drug delivery devices, ${ }^{[7]}$ contact lenses ${ }^{[8]}$ and wound healing bioadhesives. ${ }^{[9]}$ They contain a high content of water and hold their shapes while still being able to deform. ${ }^{[10]}$ Moreover, the mechanical properties (especially the stiffness) of hydrogels are comparable to many biological tissues. ${ }^{[1]}$ Due to their capability of suspending cells in 3D, supporting nutrient diffusion through their open network, ${ }^{[11,12]}$ hydrogels are one of the most promising materials for tissue engineering. It has been reported that substitutes for skin, ${ }^{[13]}$ tendon $^{[14]}$ and cartilage ${ }^{[15,16]}$ could be successfully fabricated from synthetic hydrogel constructs.

In tissue engineering, the general approach is to seed cells onto prefabricated scaffolds that support diffusion of oxygen and nutrients as well as larger ECM molecules such as collagen. For this, a wide range of hydrophilic and hydrophobic 
precursors can be used. The fabrication process may involve harsh solvents, toxic reactants and may proceed under nonviable environmental conditions (e.g., high temperature or nonphysiological $\mathrm{pH}$ value) as long as the final product is biocompatible. ${ }^{[17]}$ Cells are introduced to migrate into and populate the inner regions of the produced parts. ${ }^{[18]}$ However, the seeding approach makes it hard to control the density and the distribution of cells. ${ }^{[19,20]}$ Using hydrogel precursors crosslinked via biocompatible mechanisms, though, it is possible to form these materials in vivo, in the presence of cells and tissues, allowing to encapsulate cells during the fabrications process.

\section{Cell-Encapsulation in Hydrogel Constructs}

Cell-encapsulation offers several advantages compared to the seeding approach. Apart from achieving homogeneous cell distributions with high initial density, liquid precursor solutions with suspended cells can be directly shaped at the site of interest. The formed constructs can adhere to the surrounding without requiring adhesives or sutures. ${ }^{[17,21]}$ To exploit these advantages, the gelation process must be mild and cell friendly and the final construct suitable for cell survival and tissue formation. Furthermore, the material must degrade and the degradation product must not affect cell viability. As the natural ECMs assemble and disassemble interacting with their inherent cells, researchers have tried to mimic their properties using naturally derived materials, such as fibrin, ${ }^{[22]}$ alginate, ${ }^{[23]}$ chitosan $^{[24]}$ and hyaluronic acid $(\mathrm{HA})^{[25]}$ as well as synthetic materials such as poly(ethylene glycol) $(\mathrm{PEG})^{[26]}$ and polyfumarate. ${ }^{[27]}$ To control the properties of these gels (crosslinking density, hydrophobicity, swelling rate, permeability, degradability and mechanical strength), various stimuli facilitating hydrogel crosslinking in the presence of cells and tissue have been explored. ${ }^{[10]}$ These include physical stimuli such as temperature, pressure and solvent composition or biochemical stimuli like $\mathrm{pH}$ changes or ions. ${ }^{[28]}$ Light is of particular interest since it can be controlled with great ease and convenience. ${ }^{[10]}$ In this regard, ECM analogues were built incorporating modified proteins and glycosaminoglycans into a single polymerized matrix. ${ }^{[21]}$ Encapsulating mesenchymal stem cells in these matrices provided superior tissue regeneration mimicking the native mechanical properties and architecture of cartilage. ${ }^{[29]}$ This shows that hydrogels offer great promise in designing suitable environments that provide mechanical and chemical cues to promote cell proliferation, differentiation and tissue growth. However, transport requirements for nutrients, oxygen and large ECM molecules such as collagen increase with high cell density. ${ }^{[16,17]}$ Through the bulk of thick hydrogels with encapsulated cells, transport may be limited potentially compromising the cellular activity. Moreover, in thick samples, light attenuation becomes critical. To ensure complete conversion of precursors to polymer, potentially cytotoxic light intensities and high initiator concentrations may be necessary. ${ }^{[16]}$ A metabolically appropriate setting, suitable for maintaining physiologically high cell densities, requires a more sophisticated scaffolds design ${ }^{[30]}$ and biocompatible polymerization conditions. ${ }^{[16]}$ Besides chemical and mechanical cues, an effective ECM analogue, thus, also requires topographical similarities.

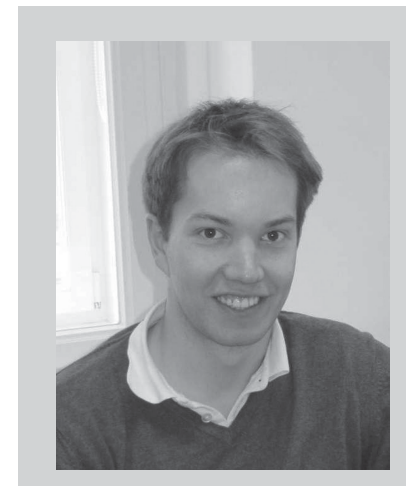

www.MaterialsViews.com

Jan Torgersen is a PhD student at the Vienna University of Technology. He completed his master thesis in mechanical engineering in 2010. In his $\mathrm{PhD}$, he focuses on two-photon polymerization for structuring hydrogels suitable for in vivo polymerization. His research interests are lithography-based additive manufacturing technologies and hydrogel biomaterials.

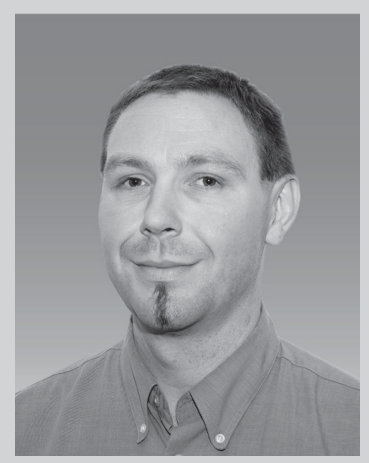

Prof. Robert Liska was born in 1969 in Vienna, Austria. He received his PhD degree in 1998 from the Vienna University of Technology where he continued his academic career afterwards. In 2006, he habilitated in the field of macromolecular chemistry. $\mathrm{He}$ is the leader of the research group "Photopolymerization" and his current research interests are in the field of photoinitiation, photopolymerization and biomedical polymers.

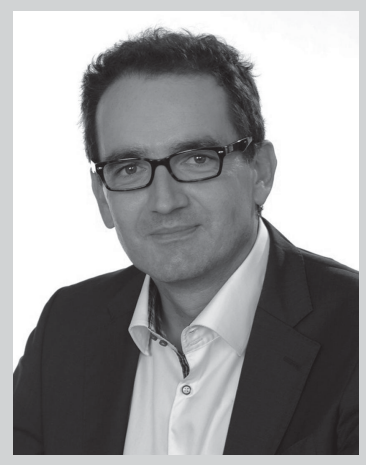

Prof. Stampfl has been working in the field of Additive Manufacturing Technologies (AMT) since 1997, when he joined the Stanford Rapid Prototyping Laboratory as a post-doctoral researcher. After returning to Austria in 2000 he set up an AMT group at TU Wien, working in the field of materials and systems development.

\section{Additive Manufacturing of Hydrogels}

To overcome the mass transport limitations, researchers fabricated porous architectures in hydrogel structures with highly interconnected pore networks. ${ }^{[31]}$ Additive manufacturing (AM) provides an effective control of complex, ECM similar architectures. In a very recent report, AM was used to create perfusable channels in ECM analogues creating vascular architectures aligned with endothelial cells and perfused with blood under high pressure. ${ }^{[30]}$

To create similar architectures directly in the presence of cells in a one-step approach, stereolithography (SLA), a 
lithography-based additive manufacturing technology (AMT) has been extensively used. ${ }^{[19,32-35]}$ In SLA, a thin film of a photoreactive formulation is exposed to UV light locally, which causes its photopolymerization. A Z-stage repetitively stacks polymer layers on top of each other. In this layer-by-layer manner, a 3D part is created according to a computer-aided design (CAD). ${ }^{[36]}$ The ability to easily create constructs according to data from clinical imaging like magnetic resonance imaging (MRI) or computer tomography (CT) renders this technique useful for biological applications. ${ }^{[19]}$ Complex hydrogel constructs with well-defined porous architectures and desired mechanical functions as well as appropriate mass transport characteristics have been created leading researchers to a better understanding of cell-matrix interactions in $3 \mathrm{D} \cdot{ }^{[37]}$ As the resolution can be adjusted down to a few micrometers, ${ }^{[38]}$ it is possible to produce hydrogel scaffolds with features in the order of $10-400 \mu \mathrm{m}$ to control the structure cluster of cells as well as features $>400 \mu \mathrm{m}$ to control the interactions between multiple cell clusters. ${ }^{[39]}$ It is possible to provide design criteria for zonal density variations of cells as existent in articular cartilage or meniscal- and osteochondral tissues. ${ }^{[40]}$

Pore sizes obtainable with SLA, are relatively large compared to the dimension of a cell. ${ }^{[41]}$ This can result in cell isolation and makes it necessary to cluster cells. ${ }^{[42]}$ To control the environment of individual cells, resolutions in the order of $0.1-10 \mu \mathrm{m}$ are necessary. ${ }^{[39]}$ In this respect, electrospinning is a diverse technique capable of producing fibril networks with fiber diameters in the sub- $\mu \mathrm{m}$ region. Encapsulating living cells during the fabrication process has also been reported. ${ }^{[43]}$ However, despite significant progress in controlling the fiber orientation, ${ }^{[44]}$ electrospinning does not allow the exact recapitulation of the entire matrix architecture. ${ }^{[45]}$ The fabricated scaffolds are ideal substrates for growing and implanting cell monolayers. However, constructs with larger pore sizes, suitable for cell invasion after seeding, have poor mechanical stability. To be effective as a scaffold, an ideal construct provides micro-features that exist in an organized 3D environment proceeding from the micro- to the macroscale facilitating effective cell migration and proliferation. ${ }^{[46]}$ Due to the uncontrollable nature of electrospinning, this technique does not meet the necessary requirements. ${ }^{[35]}$

Electrospun fibril networks have been introduced in SLA fabricated scaffolds to "sieve" individual cells. ${ }^{[40]}$ It could be shown that bovine primary chondrocytes were more efficiently retained on AMT scaffolds containing an electrospun fibril network than on those without. However, this two-step approach increases the complexity of the fabrication process, sets new limitations and reduces reproducibility. ${ }^{[35]}$ A complete understanding of the cells' behavior in respect to topographical cues requires a one-step fabrication process that is capable of reproducibly producing defined 3D structures at multiple length scales, high resolution and in accordance to a specific design.

Two-photon polymerization (2PP) is a method based on localized crosslinking of photopolymers, induced by femtosecond laser pulses. ${ }^{[35]}$ This technique allows the fabrication of feature sizes from $65 \mathrm{~nm}^{[47]}$ to close $1 \mathrm{~cm}^{[48]}$ according to a geometry defined by CAD. It is the most effective multi-photon process and relies on the principle of two-photon absorption
(2PA). In this process, a photoinitiator (PI) absorbs two-photons to be excited to an energy state similar to an excitation with one photon of higher energy. ${ }^{[49]}$ The probability of this effect depends on the photons interacting with a molecule nearly simultaneously (within a time frame of $10^{-16} \mathrm{~s}$ ) and scales quadratically with the applied laser intensity. Under tight focusing of a pulsed laser, the absorption is limited to the focal point as the number of molecules excited decreases rapidly with the distance from the intensity maximum. ${ }^{[49]}$ Thus, in contrast to SLA, polymerization is not limited to the surface of a formulation. The materials used are essentially transparent for the wavelength of the utilized laser. ${ }^{[35]} 2 \mathrm{PP}$ offers true $3 \mathrm{D}$ polymerization without the need of a layer-by-layer fabrication procedure. All shortcomings related to the surface formation, such as high viscosities of the formulation (leading to high surface tensions), the necessity of recoating, ${ }^{[50]}$ the need of supporting material ${ }^{[51]}$ and oxygen inhibition ${ }^{[52]}$ can be discarded.

Furthermore, 2PP offers mild processing conditions. It can be preformed using light of the near-infrared (NIR) spectral range. In contrast to short wavelength UV light, which can induce photochemical damage to biological tissues, ${ }^{[53,54]}$ NIR light seems to be most suitable for inducing polymerization in the presence of cells. Proteins, DNA, melanin and hemoglobin dominate tissue absorption in the UV and visible spectral range, whereas water begins to contribute significantly at $\lambda \geq 900 \mathrm{~nm}$. At $800 \mathrm{~nm}$, however, biological tissue exhibits a window of transparency where the absorption seems to be minimal. ${ }^{[55]}$

However, by tightly focusing NIR fs-laser pulses in biological tissues, it is possible to ablate components at mico- and nanometer precision without altering neighboring structures. As $2 \mathrm{PP}$ requires similar focusing, a maximum threshold of $1.5 \mathrm{~nJ}$ using a $100 \times$ NA 1.4 objective at $5 \mu \mathrm{m} \mathrm{s}^{-1}$ scanning speed has to be considered to prevent nonspecific ablation. ${ }^{[56]}$ Maintaining high cell viability, Kloxin et al. reported successful two-photon induced photodegradation of hydrogels operating below this threshold. ${ }^{[57]}$

As suitable hydrogel precursors are limited, there were only a few publications on the fabrication of hydrogel constructs with 2PP so far. Complex porous scaffolds were usually produced of synthetic commercially available sol-gel formulations showing appropriate biocompatibility and no cytotoxicity. ${ }^{[58]}$ However, these formulations render hydrophobic structures that do not swell in water. Furthermore, post processing with organic solvents is required and the obtained scaffolds do not degrade hydrolytically.

In what follows, we will overview recent advances in the fabrication of hydrogel structures using $2 \mathrm{PP}$. We will describe the necessary main components of photopolymerizable formulations that can render 2PP fabricated hydrogels capable of delivering various signals for cells. In this manner, biocompatible constructs made from naturally derived and synthetic biomaterials will be presented. We will show successful 2PP microfabrication of these materials according to a predefined CAD. Moreover, we will discuss the approach of modifying natural biomaterials and show results of 2PP in the presence of living tissues and cells. Some of the results might have involved twoor more photon-induced processes. As 2PP is the most effective and commonly used, we will stick to this term for better understandability. 


\section{Polymerizable Hydrogels}

A wide range of synthetic and naturally derived materials may be used to form hydrogels for tissue engineering. ${ }^{[3]}$ For photopolymerization, the formulation is usually liquid and should rapidly solidify upon illumination with light.[19] A photopolymerizable formulation suitable for biological applications may consists of the following components: ${ }^{[36,38,59]}$

1. A photoinitiator (PI) adsorbs incident light and readily generates reactive radicals initiating the polymerization.

2. Multifunctional crosslinkers function as links between the polymer chains. They consist of an oligomeric spacer with more than one reactive group, they define to a large extent the mechanical properties and in some cases the biodegradation of the resulting polymer.

3. Often monofunctional reactive diluents are added to tune the viscosity of the formulation. They are incorporated into the backbone of the polymer and thus can be used to further adjust the mechanical properties.

4. In the presence of a solvent like water or PEG, the polymer network is swollen, leading to a decrease in stiffness and strength of the construct compared to dry or less hydrated specimen.

5. Bioactive stimuli can be added to the formulation. These substances are major determinants for cell behavior and can be conjugated to the scaffold material. ${ }^{[60]}$

To adjust the polymer to application-specific requirements, these five components and their ratios have to be chosen properly. In the following sections, we will present results on 2PP of formulations containing different types of the respective components. We will investigate their chemical structure, their reaction mechanism under the influence of incident light and their interplay with other components. We will review successful combinations, discuss their potential for biomedical applications and show how these materials can serve as bioinspired matrices to study cell behavior in 3D.

\subsection{Water Soluble, Two-Photon Active Photoinitiators}

A two-photon PI is a photoactive molecule, which simultaneously absorbs two NIR photons upon nonlinear excitation to directly or indirectly induce the generation of free radicals for subsequent polymerization. Highly active PIs are critical for efficient 2PP characterized by a high 2PA cross section and high initiating efficiency leading to a broad processing window $^{[61]}$ and low polymerization threshold. Polymerization can be performed at only low excitation power and short exposure times leading to high polymerization speeds and high quality structures.

Successful 2PP microfabrication of cytocompatible scaffolds is conventionally performed using commercially available inorganic-organic hybrid formulations containing the UV initiator Irgacure 369 as photoinitiator. ${ }^{[58,62,63]}$ Although the 2PA cross section of Irgacure 369 is small at the desired wavelength, ${ }^{[64]}$ the limited 2PA could be compensated by high radical formation quantum yields to ensure acceptable initiation efficiency. In Table 1, PIs for the fabrication of hydrogels via $2 \mathrm{PP}$ are listed. Z-scan analysis was used to measure the 2PA cross section as two-photon analogue to the linear absorption coefficient. It is measured in Göppert-Meyer (GM) units $\left(10^{-50} \mathrm{~cm}^{4} \mathrm{~s}_{\text {photon }}{ }^{-1}\right) \cdot{ }^{[65]}$

To form hydrogels, researchers fabricated hydrophilic constructs via $2 \mathrm{PP}$ of water soluble monomers using commercial hydrophobic UV photoinitiators in the absence of water. ${ }^{[69-71]}$ Using this approach, cells cannot be incorporated in the fabrication process since they must be kept in an aqueous suspension. Moreover, the solvent-exchange from fabrication to cell seeding can lead to significant structure distortions. ${ }^{[72]}$ Thus, the main advantages of 2PP-the high resolution and the possibility of forming structures in vivo without harming biological tissuescannot be fully exploited. A strategy to improve water solubility of commercially available, hydrophobic initiators makes use of of nonionic surfactants. ${ }^{[72]}$ Jhaveri et al. increased the water solubility of commercial hydrophobic initiators (Irgacure 651 and AF240) using a nonionic surfactant (Pluronic F127). ${ }^{[72]}$ Though this approach facilitates the fabrication of hydrogel structures from an aqueous formulation, large amounts of surfactant are needed to ensure adequate initiation efficiency, which might reduce the biocompatibility. The optimization of real water soluble initiating systems for 2PP becomes important.

Irgacure 2959 was used for 2PP of 3D scaffolds due to its hydrophilicity and good biocompatibility. ${ }^{[73]}$ However, this initiator is only suitable for $2 \mathrm{PP}$ at $515 \mathrm{~nm}$ wavelength. At this wavelength, proteins absorb the laser light increasing the chance of their denaturation. ${ }^{[54]}$ Only a limited intensity can be applied in the presence of biological tissues ${ }^{[55]}$ leading to lower available energy for polymerization.

Until now, the most popular hydrophilic initiation system for 2PP is a dye-amine combination. Due to suitable absorption above $400 \mathrm{~nm}$ and easy accessibility, commercially available hydrophilic xanthene dyes, such as rose bengal, eosin and erythrosine were applied in $2 \mathrm{PP}$ of formulations with amine as coinitiator. ${ }^{[6,74]}$ In this type of initiation, the dye becomes excited by simultaneous absorption of two NIR photons via a virtual state. Accessing the second excited singlet state S2, the molecule undergoes rapid radiationless decay to $\mathrm{S} 1$, interconverting to the long-lived triplet state with high quantum (Scheme 1). ${ }^{[75,76]}$ Intermolecular electron transfer followed by hydrogen transfer from the amine to the excited dye generates active amine radicals to induce subsequent polymerization. 2PP of synthetic monomers such as pentaerythritol triacrylate $^{[74]}$ and acrylamide ${ }^{[66]}$ have been realized with dye-amine initiation systems.

However, high laser intensities $(\approx 100 \mathrm{~mW})$ and long exposure times $(300-400 \mu \mathrm{s})$ were required due to the small 2PA cross section (Table 1 ) of the dye. ${ }^{[77]}$ Additionally, some intrinsic limitations derived from bimolecular systems, such as electron transfer efficiency between dye and coinitiator or the back electron transfer, would significantly decrease the initiation efficiency.

Some hydrophilic dyes, such as rose bengal[76] and methylene blue ${ }^{[78,79]}$ could also be used to directly crosslink proteins. Since the protein itself fulfils the role of coinitiator and crosslinker at the same time, triethanolamine is not required and in fact appears to act as an inhibitor. Protein crosslinking without a coinitiator is believed to occur in one 
Table 1. 2PP PI, water solubility, availability and $2 \mathrm{PA}$ cross sections $\left(\sigma^{2 \mathrm{PA}}\right.$ in $\mathrm{GM}\left[10^{-50} \mathrm{~cm}^{4} \mathrm{~s}\right.$ photon $\left.\left.{ }^{-1}\right]\right)$ at $800 \mathrm{~nm}$ measured using Z-scan analysis.

\begin{tabular}{|c|c|c|c|c|c|}
\hline 2PP PI & Water soluble & Commercial & $\sigma^{2 P A}$ & Chemical Structure & Reference \\
\hline Irgacure 369 & No & Yes & 7 & & [65] \\
\hline Irgacure 651 & No & Yes & 28 & & [65] \\
\hline Irgacure 2959 & yes & Yes & Not known & & \\
\hline Rose Bengal & Yes & Yes & 10 & & [67] \\
\hline Eosin $Y$ & Yes & Yes & 10 & & [67] \\
\hline Erythrosin & Yes & Yes & 10 & & [67] \\
\hline $\begin{array}{l}\text { Flavin adenine } \\
\text { dinucleotide (FAD) }\end{array}$ & Yes & Yes & 0.035 & & [68] \\
\hline Methylene blue & Yes & Yes & Not known & & \\
\hline WSPI & Yes & No & 120 & & [69] \\
\hline $\mathrm{G} 2 \mathrm{CK}$ & Yes & No & 136 & & In preparation \\
\hline
\end{tabular}

of two ways, both of which involve excitation of the dye to the T1 state (Scheme 1). The excited dye can either abstract hydrogen directly from a protein molecule to induce protein crosslinking, or transfer energy to the ground state triplet molecular oxygen, producing singlet molecular oxygen. ${ }^{[75]}$ In the singlet oxygen mechanism, the active oxygen species continues to react with an oxidizable amino acid residue to generate an electron-deficient protein that may react with another protein's amino acid residue to form a covalent bond. The probability for this reaction depends on the type of amino acid residues on proteins. Protein crosslinking is different from a polymerization process. Two radicals have to be formed by 2PA to make one crosslink, which makes the process rather inefficient compared to chain growth 2PP of synthetic materials. Furthermore, though Campagnola et al. improved rose bengal and benzophenone initiation adding coinitiators to form one molecule, ${ }^{[80]}$ the $2 \mathrm{PA}$ activity of the dyes remained low. As a result, the fabrication process still requires very long exposure times and high energies. ${ }^{[72]}$

Although a full understanding of the relationship of molecular structure and two-photon properties remains a big challenge until now, 2PA PIs with high 2PA cross section combined 


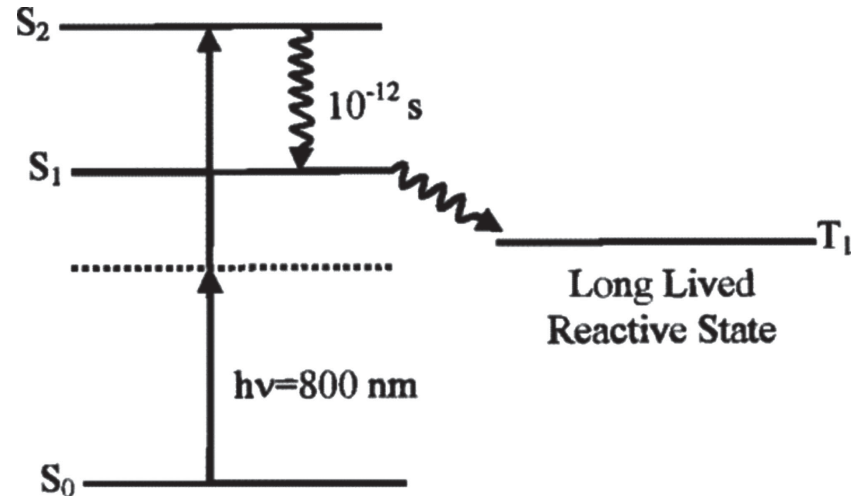

Scheme 1. Energy level diagram for two-photon excitation of rose benga. Reproduced with permission. ${ }^{[75]}$ Copyright 2000, American Chemical Society.

with a high photoreactivity (like for conventional one-photon initiators) seems the goal to be achieved. ${ }^{[81]}$ To design an ideal molecular structure with a high 2PA, several molecular key features have been identified. ${ }^{[2-84]}$ Since intramolecular chargetransfer is the "driving force" for 2PA, electron-donor and/or electron-acceptor groups are required. In addition, coplanar $\pi$-conjugated bridges leading to states with extended charge separation are critical in enhancing the efficiency of intramolecular charge transfer. Although plenty of 2PA active hydrophilic chromophores have been reported, nearly all of them are fluorescent dyes for bioimaging applications ${ }^{[85,86]}$ and are not suitable for inducing photopolymerization. For an effective 2PA PI, low fluorescence quantum yields are preferred leading to a higher population of active states to initiate subsequent polymerization.

The most effective way to produce efficient water soluble 2PA PIs is to introduce water-borne functional groups, such as quaternary ammonium cations or different carboxylic sodium salts into the known core structures possessing high 2PA activity. Suitable spacers like alkyl-chains are usually required to avoid shifting the electronic structure of the 2PA chromophore. A distyrylbenzene chromophore (WSPI) (Table 1) with quaternary ammonium cations was initially synthesized to study the solvent effects on the 2PA behavior. ${ }^{[68]}$ Since $4,4^{\prime}$-dialkylaminobis(styryl)benzene proved to be a potent 2PA $\mathrm{PI}{ }^{[87]}$ high 2PA initiation efficiency of WSPI in aqueous formulation is expected. Using WSPI as an efficient initiator, our group fabricated 3D hydrogel scaffolds in the presence of a living organism for the first time (see Section 4.2.1). ${ }^{[8]}$ Following the same strategy, Wu's group successfully synthesized benzylidene cyclopentanone dyes with hydrophilic sodium carboxylate group at the terminal alkyl chains. They applied the molecule as water soluble 2PA sensitizer combined with trietanolamine for 2PP under aqueous condition. ${ }^{[77]}$ Our latest study on a series of hydrophobic benzylideneketone dyes shows that different sizes of the central rings have significant effects on their activity as initiators for $2 \mathrm{PP}$. ${ }^{89]}$

Our group recently prepared a series of cyclic benzylidene ketone based water soluble 2PA PIs with different sizes of central rings. The 4-methylcyclohexanone based initiator $\mathrm{G} 2 \mathrm{CK}$

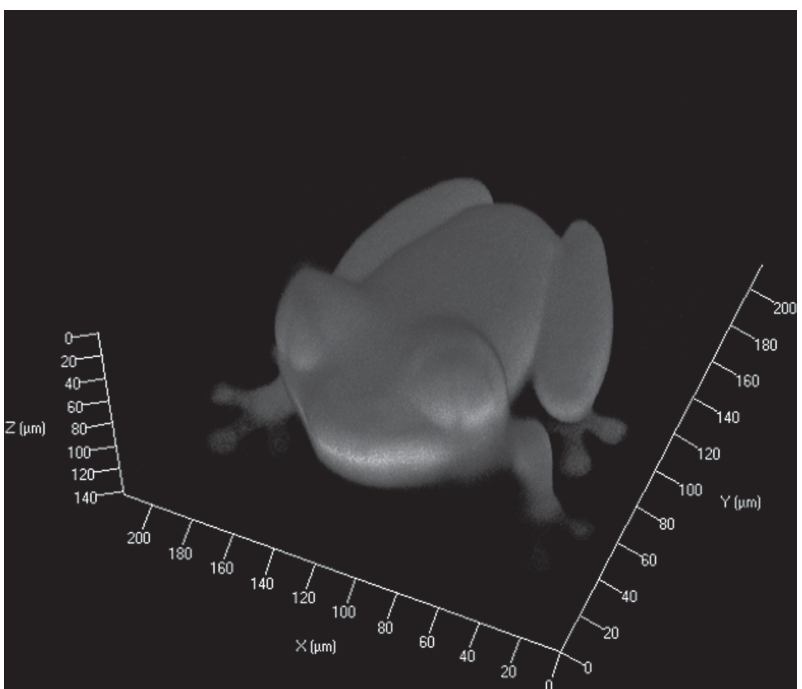

Figure 1. Laserscanning microscope (LSM) image of a hydrogel structure made from a formulation containing $50 \mathrm{wt} \%$ water using G2CK as initiator.

(central five member ring, Table 1) showed broader processing windows than its counterparts and as the reference molecule WSPI. Complex structures could be fabricated at high fabrication speed using 50\% PEG-diacrylates (PEGda) based formulations dissolved in aqueous solution (Figure 1). Moreover, the cytotoxicity of G2CK is comparable with Irgacure 2959 when exposing MG 63 cell lines to the molecules in cell culture media (manuscript in preparation).

\subsection{Biopolymers}

Although the access to highly efficient water soluble twophoton PIs is a prerequisite for 2PP of hydrogels, the selection of appropriate photopolymerizable monomers/macromers as hydrogel precursors is equally important. To develop one formulation for 2PP of hydrogels, the precursors have to meet several requirements.

First, the precursor should possess sufficient water solubility. To meet this requirement, PEG based synthetic monomers as well as certain natural polymers (e.g., HA) have drawn wide interest due to their superior hydrophilicity. ${ }^{[90]}$

Second, from a biological point of view, the hydrogel precursor has to face three major challanges:

- For in vivo 2PP, cells and tissues are exposed to the unpolymerized formulation, the polymerization reaction and to the final polymerized structure. Thus, the unpolymerized precursors and their polymerization reaction must be cytocompatible.

- After 2PP microfabrication, the precursors determine the sustainability of cell viability and further cell functions (proliferation, differentiation, etc.). ${ }^{[91]}$

- To guide cells to specific directions in 3D, additional cues should be provided. An incentive for cell attachment to the polymer should be given; the materials should be bioactive. 
In natural ECMs, cell attachment is regulated by the crosstalk between integrin receptors on cell membranes and integrin binding motifs (e.g., RGD peptides). As known from cell encapsulation studies, naturally derived proteins with cell adhesive ligands (e.g., collagen, gelatin, fibrinogen) or synthetic materials with incorporated ligands are promising materials for providing similar environments. ${ }^{[73]}$

Third, the photo-reactivity of hydrogel precursor plays an important role in the feasibility for $2 \mathrm{PP}$. To obtain $\mathrm{mm}$ sized structures in a reasonable time, the formulation has to be processed at high writing speed and high pulse energies without compromising the quality of $2 \mathrm{PP}$ printed structures and its desired feature sizes. ${ }^{[92]}$

With these criteria in mind, we review reported materials suitable for 2PP of hydrogels. These materials are divided into three groups: synthetic polymers, native proteins and chemically modified natural polymers. Furthermore, we will show their potential for investigating cell responses to different isolated cues.

\subsection{Synthetic Polymers as Hydrogel Precursors}

A suitable biomaterial must withstand the normal loads and stresses of native tissues and has to degrade while still providing a temporal support. Whereas the mechanical properties of natural derived polymers are often inferior compared to their natural counterparts, ${ }^{[93]}$ the chemistry and properties of synthetic materials, in contrast, can be controlled reproducibly. ${ }^{[3]}$ To meet different application specific requirements, synthetic materials are produced tuning molecular weights, block structures, degradable linkages and crosslinking modes. PEG is a potential key component of synthetic precursors, since it is widely used in tissue engineering and is FDA approved for various medical applications. It can be found in cosmetics, lotions, soaps and drug formulations.

In order to functionalize PEG with (meth)acrylates, photocrosslinkable formulations are created that can form hydrogels with a wide range of physical properties. ${ }^{[3,94]}$ In this regard, these polymers are cytocompatible, nonimmunogenic, bio-inert to cells, tissues and drugs and inherently resistant to protein absorption. ${ }^{[95,96]}$ PEG based hydrogels facilitate the exploration of mechanical (elastic modulus, mesh size), geometrical (architecture) and chemical (cell adhesions peptides) effects disregarding the polymer's bioactivity as design variable. ${ }^{[60]}$ Furthermore, the mechanical properties and mesh sizes of PEG based hydrogel constructs can be controlled over a wide range simply by varying the molecular weight and/or the concentration of photopolymerizable PEG. ${ }^{[94]}$

Using PEG as an inert substrate, researchers identified the role of molecules for regulating specific cell-ECM interactions mediated via adhesion molecules such as fibronectin and laminin. These molecules induce the arrangement and polymerization of the cell's cytoskeleton. ${ }^{[97]}$

The group of JL West guide cells in 3D using the chemical attributes of bound growth factors within an existing PEG based hydrogel. ${ }^{[98]}$ They synthesized proteolytically degradable PEGda monomers by introducing a collagenase-sensitive protein linker into the PEG backbone. Human dermal fibroblast clusters in fibrin hydrogels were added to a photopolymerizable PEG solution and cured under UV light in the presence of cells. A solution containing the fibronectin derived peptide arginineglycine-aspartic acid (RGD) bound to modified PEG-acrylates was soaked into the hydrogel. After this preparation, patterns of proteins could be bound to the hydrogel locally by 2PP in the presence of a photoinitiator solution (2,2-dimethoxy-2-phenylacetophenone in $n$-vinylpyrrolidone). It could be shown that fibroblasts migrated out from the fibrin into the degradable PEG hydrogel networks, whereas cells entrapped in degradable PEG hydrogels without patterns stayed in the fibrin. The same group later patterned multiple peptide moieties within the same hydrogel sample. ${ }^{[9]}$ Furthermore, they showed the local acceleration of endothelial cells' tubulogenesis and angiogenesis by covalently binding VEGF (glycosaminoglycans also present in the native ECM) and integrin ligands to the existing hydrogel. ${ }^{\text {99] }}$

The group of KS Anseth at the University of Colorado (CO, USA) developed synthetic PEG hydrogels that can be modulated on demand. They synthesized monomers capable of polymerizing in the presence of cells rendering cytocompatible hydrogel structures. ${ }^{[100]}$ By introducing a nitrobenzyl ester-derived moiety into the PEG backbone (Scheme 2), the hydrogel can be cleaved via fs NIR light and thus spatially and temporally tuned in its physical and chemical properties. Besides these topographical cues, the group was also able to immobilize thiol-containing biomolecules within a click-based hydrogel (Scheme 2). ${ }^{[101]}$ Upon gel formation, the hydrogel was soaked with fluorescently labelled, thiol-containing biomolecules together with a water soluble photoinitiator (eosin Y). Three dimensional biochemical patterns were created at high resolution $(1 \mu \mathrm{m} \mathrm{X/Y,}$ 3-5 $\mu \mathrm{m} \mathrm{Z}$ ). The process was repeated to provide multiple adhesive signals relevant for many cell types. The group later synthesized biological molecules containing thiol groups for photocoupling and photolabile moieties for photocleavage to and from the PEG based hydrogel. ${ }^{[102]}$ This way, they showed the photomediated introduction of the cell adhesion ligands (RGD) as well as their removal using different wavelengths of NIR fs

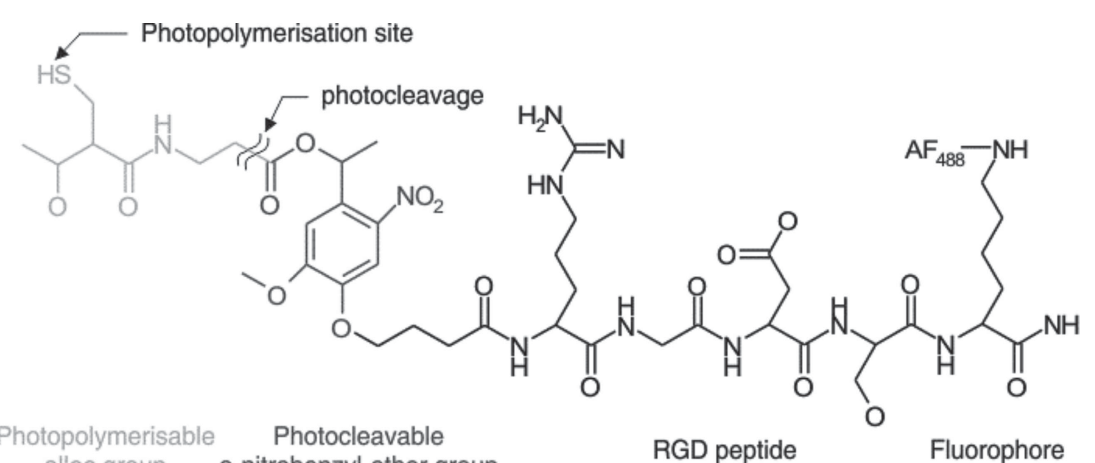

alloc group o-nitrobenzyl-ether group

Scheme 2. RGD peptide (black) fluorescently labelled with the fluorophore Alexa Fluor 488 $\left(\mathrm{AF}_{488}\right)$ bound to photocleavable o-nitrobenzyl ether (dark grey) and photopolymerisable alloc groups (light grey); the molecule can be reversibly polymerized to a PEG based hydrogel via thiol-ene photoreaction. Adapted with permission. ${ }^{[102]}$ Coypright 2012, Wiley-VCH. 


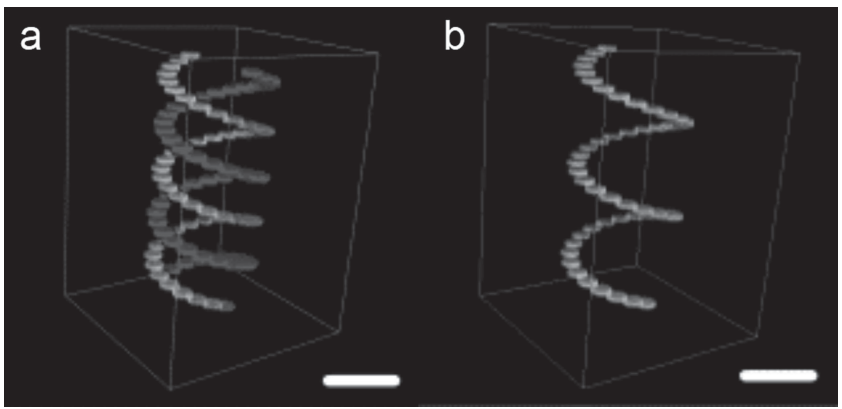

Figure 2. a) Two-photon patterned fluorescent peptide inside the preformed hydrogel (carried out at $860 \mathrm{~nm}$ wavelength) and b) after cleavage of the dark grey areas (740 nm wavelength), Scale bar $200 \mu \mathrm{m}$, LSM images. Reproduced with permission. ${ }^{102]}$ Copyright 2012, Wiley-VCH.

laser (860 $\mathrm{nm}$ and $740 \mathrm{~nm}$, respectively, see Figure 2), all in the presence of cells. Embryonic fibroblasts were seeded onto specimens containing patterned islands of RGD. Cells attached to these islands but detached within minutes upon their removal. These constructs provide a dynamic simplified synthetic environment with full spatiotemporal control. Single factors can be varied selectively to explore a better understanding of cell-material interactions existent in the native ECM.

Besides the binding of growth factors to and from existing PEG matrices, researchers have been able to build up 3D structures and scaffolds from modified PEG monomers, too. However, so far, commercially available, water soluble initiators were not used to crosslink modified PEG. Highly porous scaffolds out of PEGda (Mn 700) were fabricated using a commercial, organo-soluble photoinitiator (Irgacure 369, Table 2) ${ }^{[70]}$ at 200 $\mathrm{nm}$ accuracy. ${ }^{[71]}$ The unpolymerized residue could be washed away with water to render complex 3D hydrogel structures. Their cytotoxicity was evaluated using mouse fibroblasts, 3T3 cells and chondrocytes. ${ }^{[69,71]}$ It could be shown that the initiator content plays a key role in the biocompatibility of the constructs post fabrication.

Claiming the low 2PA cross section of conventional dyes for microfabrication in an aqueous surrounding (section 3), Jhaveri et al. dissolved commercially availbale hydrophobic initiators (Irgacure 651 and AF240) in water using a non-ionic, FDA approved surfactant (Pluronic F127). ${ }^{\text {72] }}$ This way, the successful one-step additive 2PP of simple 2D structures from PEGda (Mn 575) and 2-hydroxyethyl methacrylate from formulations with water contents of up to $40 \mathrm{wt} \%$ was reported. Our group recently modified a highly active $2 \mathrm{PA}$ dye used for biological imaging for direct 2PP of PEGda in an aqueous media. Complex porous scaffolds at $<1 \mu \mathrm{m}$ resolution could be obtained in a formulation containing $80 \mathrm{wt} \%$ water. These complex structures can be created in the presence of multicellular organisms of type Caenorhabditis elegans (Figure 3). ${ }^{[88]}$

Although PEGda has shown the feasibility for 2PP of hydrogels, the cytocompatibility of acrylates is still in doubt. It is well known that acrylates are good Michael acceptors which makes them potentially cytotoxic or even carcinogenic. ${ }^{[114]}$ This might preclude PEGda from many further clinical applications. Until now, only hydrophobic inorganic-organic hybrid formulations
Table 2. 2PP hydrogel formulations and references.

\begin{tabular}{|c|c|c|c|}
\hline Monomer & $\begin{array}{l}\text { Aqueous } \\
\text { Formulation }\end{array}$ & Initiator & Reference \\
\hline \multirow[t]{3}{*}{ PEGda } & No & Irgacure 369 & {$[70,91,103,104]$} \\
\hline & No & Michler's ketone & [71] \\
\hline & Yes & WSPI & [88] \\
\hline HA-MA/Acrylamide & No & Irgacure 369 & [95] \\
\hline Modified Gelatin & Yes & Irgacure 2959 & {$[73,105]$} \\
\hline PEGda/HEMA & Yes & AF240/Irgacure 651 & [72] \\
\hline \multirow[t]{3}{*}{ BSA } & Yes & $\begin{array}{l}\text { Rose Bengal/ } \\
\text { modified }\end{array}$ & {$[75,80,106]$} \\
\hline & Yes & Methylene blue & [107-109] \\
\hline & Yes & FAD & {$[78,110]$} \\
\hline \multirow[t]{2}{*}{ Lypholized BSA } & Yes & Eosin $Y$ & [79] \\
\hline & & Methylene blue & [79] \\
\hline \multirow[t]{2}{*}{ Collagen } & Yes & $\begin{array}{l}\text { Modified rose } \\
\text { bengal }\end{array}$ & {$[76,80]$} \\
\hline & Yes & Riboflavin & [111] \\
\hline Firbinogen & Yes & Rose Bengal & {$[75,112]$} \\
\hline Fibronectin & Yes & Rose Bengal & [113] \\
\hline Concanavalin A & Yes & Rose Bengal & [113] \\
\hline $\begin{array}{l}\text { Cytoplasmic proteins } \\
\text { in live cells }\end{array}$ & Yes & Rose Bengal & [76] \\
\hline
\end{tabular}

containing the less irritant methaccrylates as photocrosslinkable moiety were processed with 2 PP. ${ }^{[58]}$ Even with high efficient initiators, we could not fabricate satisfying structures from PEG dimethacrylates (data not shown).

We recently established a new series of alternative monomers (vinyl esters VEs) with superior cytocompatibility. ${ }^{[14,115]}$ Comparative cytotoxicity studies on osteoblasts proved that VEs are at least one and two orders of magnitude less toxic than their methacrylate and acrylate references, respectively. A comparative analysis of acrylates and VEs in terms of degradation is given in Table 3.

Biodegradability is a key prerequisite of hydrogel precursors for potential biomedical applications. ${ }^{[116]}$ When one uses PEGda

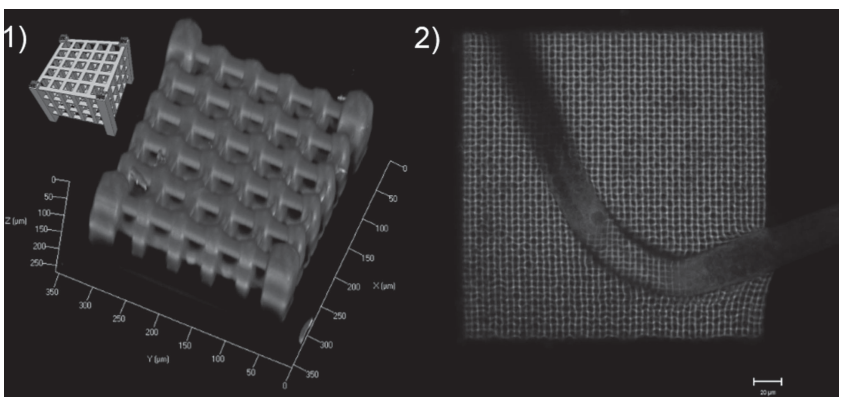

Figure 3. LSM image (1) of scaffold $280 \mu \mathrm{m} \times 280 \mu \mathrm{m} \times 225 \mu \mathrm{m}$ fabricated using a formulation containing $80 \%$ water, Image (2) shows a Caenorhabditis elegans captured in woodpile structure with $200 \mu \mathrm{m}$ side length. Adapted with permission. ${ }^{[88]}$ Copyright 2012, SPIE. 
Table 3. Comparison between acrylates and vinyl esters (VEs) regarding degradation products and hydrolyzed molecules originating from residual monomers.

Monomers

a) $\mathrm{AcDH}=$ acetaldehyde dehydrogenase; $\mathrm{NADH}=$ nicotinamide adenine dinucleotide.

as hydrogel precursor, the main degradation products are noncytotoxic PEG but also high Mw poly (acrylic acid) which is very hard to be excreted out of the human body. ${ }^{[115]}$ In contrast, the degradation product of the polymer backbone of VEs is low $\mathrm{Mw}$ poly(vinyl alcohol) recognized as an ideal building block for the creation of novel biocompatible materials.

Since it is unlikely to reach complete conversion of vinyl groups in radical photopolymerization, careful attention should be paid to the remaining unpolymerized reactive groups (at least $10-20 \%$ ). The remaining acrylate groups would form cytotoxic acrylic acid as degradation product while the left VE groups would release acetaldehyde that can easily be metabolized into acetic acid in the presence of acetaldehyde dehydrogenase. Although VEs are generally not as photoreactive as their acrylate references, our recent work found that the thiol-ene photo-click chemistry could greatly improve the reactivity of VE even to the level of acrylates. ${ }^{[117]}$ However, 2PP of constructs from water based formulations containing VEs as reactive monomers was not yet reported. Nevertheless, these compounds are promising hydrogel precursors and might play a role in the creation of biocompatible aqueous resins in the future. A respective modification of PEG will be likely.

\subsubsection{Native Proteins/Protein Precursors}

Since synthetic polymers generally lack of bioactivity, commercially available natural polymers have been explored as substrates for 2PP hydrogels. In this respect, macromeres derived from natural polymers are of interest. ${ }^{[95]}$

Campagnola and co-workers performed seminal work on 2PP fabrication of 2D simple structures by using native bovine serum albumin (BSA). ${ }^{[75,80]}$ BSA is similar to human serum albumin. It is a monomeric protein with high solubility in water and a lack of a carbohydrate moiety. Being a product of the liver, it serves as carrier of ions, fatty acids, metabolites, bilirubin, drugs and hormones. ${ }^{[118]}$

The photoinduced crosslinking reaction of BSA is based on several oxidizable amino acid residues (e.g., Tyr) present in BSA. ${ }^{[119]}$ A detailed mechanism (e.g., di-tyrosine crosslinking) is shown in Scheme 3. The crosslinking reaction starts from the excitation of a photosensitizer into the triplet state. These photoexcited species are expected to oxidize tyrosine residues. ${ }^{[119]}$ The resultant tyrosyl radical is isomerizationstabilized and can recombine with a second tyrosyl radical of another protein nearby. Therefore, intermolecular crosslinks could be formed between proteins.

Besides BSA, Campagnola's group also crosslinked other proteins with oxidizable units via $2 \mathrm{PP}$. In this respect, it was possible to process native ECM proteins like collagen $I^{[80]}$ fibrinogen, concanavalin A and fibronectin. ${ }^{[13]}$ Different native proteins contain different cell adhesive ligands. After crosslinking the protein matrices, cell adhesion and migration could be observed in response to chemical cues provided by collagen and fibrinogen in contrast to BSA.[112,120] Also multiprotein matrices made from BSA and fibrinogen in a 1:1 molar ratio were built. ${ }^{112]}$ To isolate cellular processes, the same group later fabricated channels and compartments inside live cells (starfish oocyte) crosslinking endogenous cytoplasmic proteins. ${ }^{[76]}$

The group of JB Shear from the Institute for Cellular and Molecular Biology from the University of Texas (USA) found a variety of uses to engineer biological micro-scale devices from crosslinked natural proteins. BSA and avidin microstructures were created in the presence of cortical neurons without compromising cell viability using flavin adenine dinucleotide (FAD) as photosensitizer. The neuron's contact position could be guided with micrometer-scale resolution. ${ }^{[110]}$ To further explore responses of neuroblastoma-glioma cells to physiochemical cues, they later fabricated large aspect ratio structures, manipulated portable protein microparticles by fs-pulsed NIR light induced optical
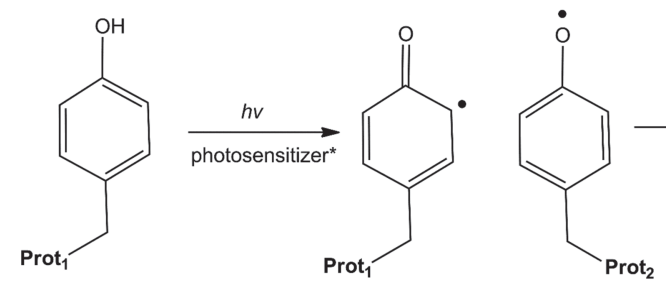

tyrosyl radicals

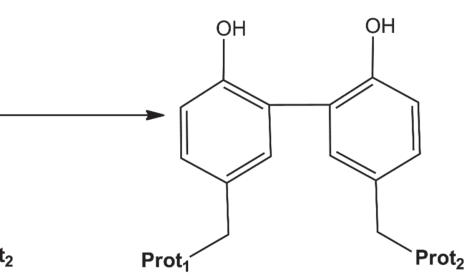

di-tyrosine crosslinking

Scheme 3. Mechanism of photoinduced crosslinking reaction of native proteins 

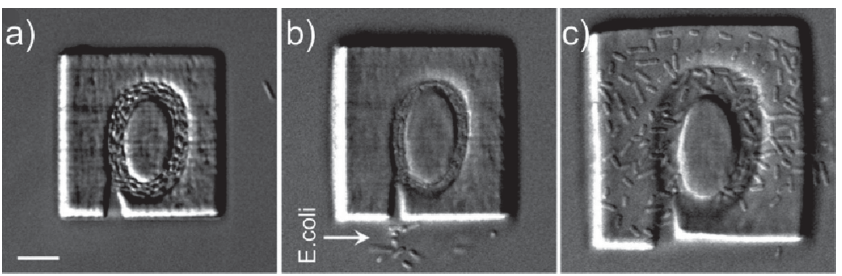

Figure 4. a) $\mathrm{pH}$-responsive microchamber for control over 3D cell culture, abrupt changes in $\mathrm{pH}$ (from 7 to 12.2), causes temporary compression of the internal chamber, releasing a few E. coli (b), or eventually disrupt the substrate interface (c), differential interference contrast images. Reproduced with permission. ${ }^{[108]}$ Coypright 2008, The National Academy of Sciences of the USA.

trapping and directly patterned enzymes on existing matrices. ${ }^{[107]}$ For creating real 3D guidance of dorsal root ganglions and hippocampal neuronal progenitor cells, BSA micropatterns were fabricated inside an existing HA hydrogel. These structures were decorated with laminin-derived peptides using avidin linkages to promote cell adhesion and proliferation. ${ }^{[78]}$ This way they can interact with the biological tissue during its development providing physical and chemical cues.

Another approach by the Shear group was to use protein microstructures as compartments for cells and bacteria to study their behavior in response to different stimuli. By incorporation of microscopic thickness and density gradients in crosslinked proteins containing poly(methyl methacrylate) particles, stimuli-responsive structures could be fabricated that underwent large volume changes upon changes in the $\mathrm{pH}$ value. ${ }^{[108]}$ This way, the fabricated microenclosures could trap, incubate and release Echerichia coli bacteria (Figure 4). Harper et al. could recently physically isolate single cells from their surrounding and entrap them in BSA microchambers. Cells remained accessible for chemically cues through the permeable walls of the microstructures. ${ }^{[109]}$ This approach allowed studying a variety of cell functions ranging from single cell biochemistry to perturbation and analysis of small populations of cultured cells upon their exposition to chemical cues.

Delicate microstructures can be fabricated out of native proteins such as BSA. The mechanical properties can be adjusted altering the laser intensity necessary for the fabrication. ${ }^{[121]}$ However, the efficiency of di-tyrosine crosslinking of natural proteins is quite limited when compared to the conventional chain growth polymerization of synthetic polymers. In the former process, a minimum of two excited photosensitizers form two tyrosyl radicals that have to couple with each other to form only one crosslink (Section 4.1). Only one radical is needed to start the chain growth polymerization in the latter approach, the crosslinking of synthetic based polymers. In a recent report, precise BSA structures were fabricated at a writing speed of only $6 \mu \mathrm{m} \mathrm{s}^{-1}$ using a $100 \times$ NA 1.4 objective. ${ }^{[79]} 2 \mathrm{PP}$ of synthetic hydrogels can proceed at $10 \mathrm{~mm} \mathrm{~s}^{-1}$ using a $20 \times \mathrm{NA}$ 0.4 microscope objective, drastically reducing the fabrication time. ${ }^{[8]}$ Though single cells and small cell clusters can be addressed using photoinitiator). crosslinked natural derived polymers as precursors, the creation of millimeter-sized constructs, sizes suitable for a large variety of biological assays, is not economically feasible. To get relevant samples still promoting cell adhesion and proliferation, 2PP of natural precursors has to proceed faster.

\subsubsection{Modified Natural Polymers as Hydrogel Precursors}

To achieve high reactivity and good biocompatibility of 2PP formulations, researchers have turned to use chemically-modified natural polymers. For instance, methacrylated HA (HA-MA) has been explored as hydrogel precursor in a recent study by Berg et al. ${ }^{[5]}$ In this work, HA-MA was prepared through a reaction between primary hydroxyl groups of HA and methacrylic anhydride. While the 2PP feasibility was proved in this work, writing speed $\left(150 \mu \mathrm{m} \mathrm{s}^{-1}\right)$ was very low. Furthermore, acrylate-based monomers (20 wt\% acrylamide and $1.2 \mathrm{wt} \% \mathrm{~N}$, $\mathrm{N}$-ethylene bisacrylamide, w/v) were added into the hydrogel precursors, presumably because the photoreactivity of the HA-MA was not sufficient.

Ovsianikov et al. recently reported the 2PP of methacryamide derivatives of gelatin (GelMOD) using Irgacure 2959 as photoinitiator. ${ }^{[73,105]}$ GelMOD was prepared through an amidation reaction between $\varepsilon$-amino groups of lysine units in gelatin and methacrylic anhydride. ${ }^{[122]}$ This work shows the successful fabrication of complex CAD based scaffolds with 3D features allowing a bioadhesive environment with accurate 3D topography. The constructs preserved their enzymatic degradation capabilities after the fabrication. In contrast to the AM of pure proteins, the writing speed could be as high as $10 \mathrm{~mm} \mathrm{~s} \mathrm{~m}^{-1}$ allowing for shorter fabrication times. Mesenchymal stem cells were seeded on the scaffolds, adhered and differentiated into osteogenic lineage.

To tackle the reactivity issue further, we recently synthesized the VE derivative of gelatin (GH-VE), which is supposed to be more cytocompatible and enzymatically degradable (manuscript in preparation). As the photoreactivity of GH-VE towards homopolymerization was quite limited, we turned to the more efficient thiol-ene click chemistry. A proposed mechanism for the robust thiol-VE photo-click reactions is shown in Scheme 4. The reason for the robustness of such reactions

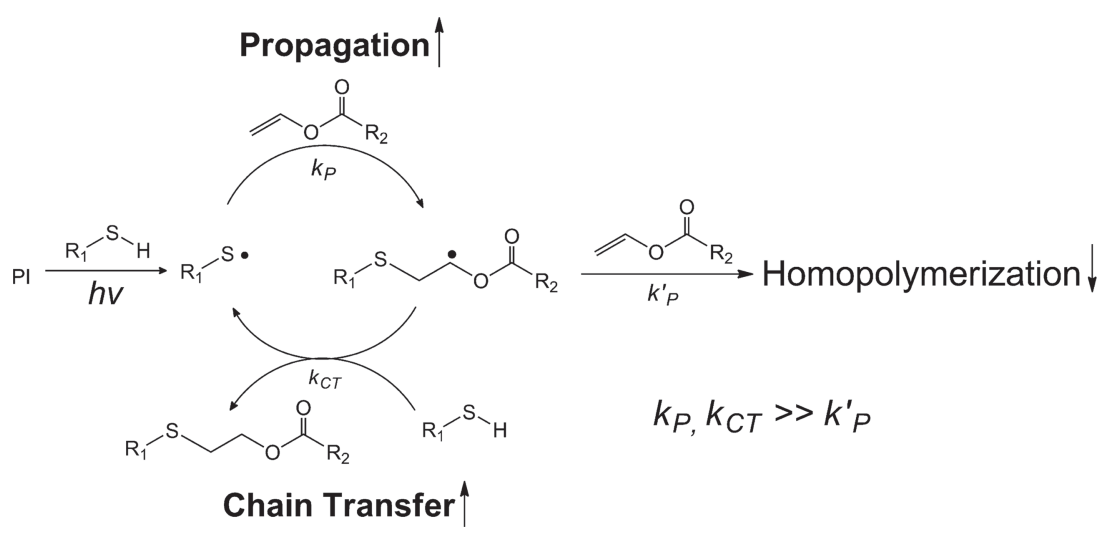

Scheme 4. Proposed mechanism of radical-mediated thiol-VE photopolymerization $(\mathrm{PI}=$ 

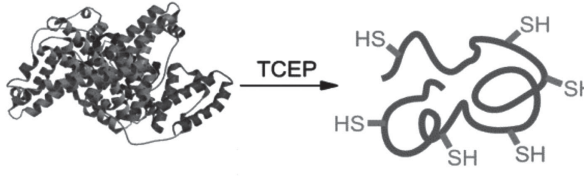

BSA

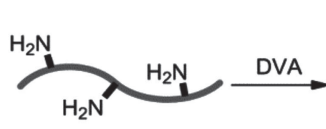

GH

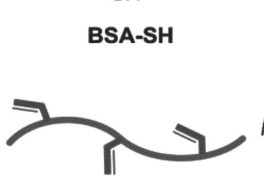

GH-VE

Scheme 5. Schematics of photocrosslinked hydrogel networks using GH-VE and BSA-SH as precursors. TCEP $=$ tris (2-carboxyethyl) phosphine.

could be addressed to the highly efficient chain-transfer reactions from carbon-centered radicals to the thiol radicals. ${ }^{[17]}$

Reduced BSA (BSA-SH) as a model macrothiol was chosen to provide multiple free cysteine units for subsequent photoclick reactions with VE groups in GH-VE (Scheme 5). Since the extent of cysteine units depends on the stoichiometry between disulfide bridges and reducing agent, varying ratios between thiol groups and VE groups could be obtained, thus providing hydrogels with tunable physical properties.

3D CAD scaffolds with complex geometry were designed according to previously successful scaffold designs. ${ }^{[72]}$ Welldefined hydrogel network structures were written within the GH-VE/BSA-SH matrices (see Figure 5). High writing speeds (as high as $50 \mathrm{~mm} \mathrm{~s}^{-1}$ ) were achieved presumably due to the robustness of thiol-VE click reactions. The accuracy was $\approx 1 \mu \mathrm{m}$ and real 3D topological features (overhangs) could be achieved.

Although BSA is known as a biocompatible component, it resists cell adhesion due to the negative charge on its surface. ${ }^{[123]}$ Preliminary cell studies proved that GH-VE/BSA-SH based hydrogels were cytocompatible with MG63 cells. Cell attachment could be adjusted by tuning the relative ratio between GH-VE and reduced BSA. These results show that GH-VE supports cell adhesion. Since reduced BSA was used as a model protein to donate free cysteines, further work using alternative disulfiderich proteins that are more cell adhesive is under way.

\section{2PP Processing Time}

A critical issue of $2 \mathrm{PP}$ is the processing time. At this stage of research, fabricating millimeter sized constructs might take a few hours or even days. As for systematic biological studies a

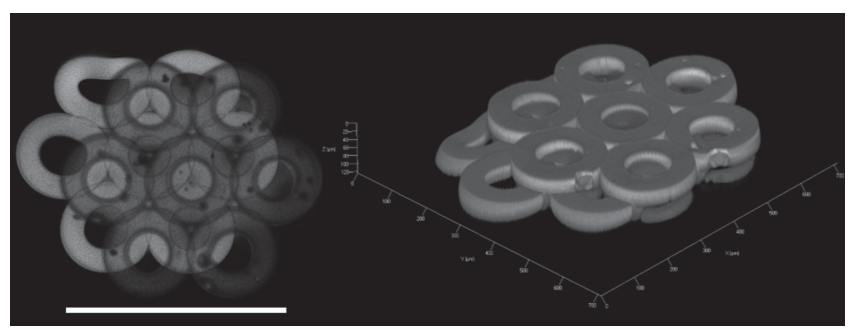

Figure 5. 2D and stacked 3D LSM images of microfabricated porous structures via 2PP; $15 \mathrm{wt} \%$ BSA-SH and $10 \mathrm{wt} \% \mathrm{GH}-\mathrm{VE}, 0.5 \mathrm{wt} \%$ WSPI in PBS, thiol:ene $=10 \%$, LSM images, scale bar $500 \mu \mathrm{m}$ series of these constructs is required, the fabrication time has to be reduced to make this process more economic.

Researchers are currently working on highly efficient chemistry to speed up the process. ${ }^{[124]}$ Reactive initiators are required that can be dissolved in water and do not compromise cytocompatibility are of particular interest. In this respect, especially the efficient formation of radicals suitable for initiating polymerization in the presence of cells will be a major issue for future investigations. Researchers have to overcome the trade-off between high reactivity and biocompatibility.

However, efficient chemistry alone is not the only issue to address. 2PP hardware must be capable of processing the formulations at high speed and submicron accuracy. High laser intensities as well as precise and fast mechanics are indispensable. Using home-built systems, Malinauskas and co-workers have fabricated close to $1-\mathrm{cm}$ sized scaffolds from hydrophobic formulations ${ }^{[48]}$ at a scanning speed of up to $100 \mathrm{~mm} \mathrm{~s}^{-1}$.125] Our group recently developed an experimental system that can fabricate at writing speeds of up to $500 \mathrm{~mm} \mathrm{~s}^{-1}$. $^{[126]}$ Hydrogels with water contents of $50 \%$ could be processed at $100 \mathrm{~mm} \mathrm{~s}^{-1}$. To fabricate at multiple sites, Ritschdorff et al. implemented a dynamic mask enabling the independent generation of features simultaneously using one laser. ${ }^{[106]}$ Together with efficient chemistry allowing for high writing speed, this can open a route to use 2PP economically for a variety of biological applications.

\section{Conclusion}

Two-photon polymerization (2PP) is a versatile technique for creating topographical, chemical and mechanical cues relevant for mimicking key elements of the natural ECM. 2PP is usually induced via fs-pulsed near-infrared laser light (NIR). At this wavelength, biological tissue and cells absorb light only minimally. Operating below a pulse energy of $1.5 \mathrm{~nJ}, 2 \mathrm{PP}$ can be performed in vivo, in the presence of biological tissues and cells. So far, these advantages could not be exploited as biocompatible, water based resins rendering body-similar hydrogel structures were not available. Over recent years, a fast growing variety of synthetic (based on poly ethylene glycol) and natural derived (e.g., serum albumin and fibrinogen) formulations have been processed in vivo. This allows the local customization of the cell environment during its development and the investigation of their behavior to specific cues excluding other influencing factors. Efficient chemistry and hardware optimizations will potentially make $2 \mathrm{PP}$ increasingly attractive for a variety of biological applications, where, ultimately, research will lead us to a better understanding of cell-cell and cell-ECM interactions.

\section{Acknowledgements}

The presented work was financially supported by the European Comission under contracts 260043 (PHOCAM) and 262027 (LebMEC) the China Scholarship Council (CSC) and the European Science Foundation (P2M 
Network). We thank Klaus Cicha and Klaus Stadlmann for the fruitful discussions and their technical assistance with the 2PP setup.

Received: December 30, 2012 Revised: February 27, 2013 Published online

[1] J. Patterson, M. M. Martino, J. A. Hubbell, Mater. Today 2010, 13, 14-22.

[2] H. K. Kleinman, D. Philp, M. P. Hoffman, Curr. Opin. Biotechnol. 2003, 14, 526-532.

[3] J. L. Drury, D. J. Mooney, Biomaterials 2003, 24, 4337-4351.

[4] F. P. W. Melchels, M. A. N. Domingos, T. J. Klein, J. Malda, P. J. Bartolo, D. W. Hutmacher, Prog. Polym. Sci. 2012, 37, 1079-1104

[5] X. Liu, P. X. Ma, Ann. Biomed. Eng. 2004, 32, 477-486.

[6] A. G. Mikos, M. D. Lyman, L. E. Freed, R. Langer, Biomaterials 1994, 15, 55-58.

[7] A. S. Hoffman, Adv. Drug Delivery Rev. 2012, 64, 18-23 (Supplement).

[8] N. A. Peppas, J. Z. Hilt, A. Khademhosseini, R. Langer, Adv. Mat. 2006, 18, 1345-1360.

[9] E. Lih, J. S. Lee, K. M. Park, K. D. Park, Acta Biomater. 2012, 8, 3261-3269.

[10] I. Tomatsu, K. Peng, A. Kros, Adv. Drug Delivery Rev. 2011, 63, 1257-1266.

[11] J. Stampfl, R. Liska, in Stereolithography (Ed: P. J. Bártolo) Springer US, Boston, MA, 2011, S. 161-182.

[12] J. A. Burdick, K. S. Anseth, Biomaterials 2002, 23, 4315-4323.

[13] C.-D. Young, J.-R. Wu, T.-L. Tsou, Biomaterials 1998, 19, 1745-1752.

[14] M. Kobayashi, J. Toguchida, M. Oka, J. Biomed. Mater. Res. 2001, $58,344-351$.

[15] J. Elisseeff, W. McIntosh, K. Anseth, S. Riley, P. Ragan, R. Langer, J. Biomed. Mater. Res. 2000, 51, 164-171.

[16] S. J. Bryant, K. S. Anseth, Biomaterials 2001, 22, 619-626.

[17] G. D. Nicodemus, S. J. Bryant, Tissue Eng., Part B 2008, 14, 149-165.

[18] V. Chan, P. Zorlutuna, J. H. Jeong, H. Kong, R. Bashir, Lab Chip 2010, 10, 2062.

[19] F. P. W. Melchels, J. Feijen, D. W. Grijpma, Biomaterials 2010, 31, 6121-6130.

[20] K. F. Leong, C. M. Cheah, C. K. Chua, Biomaterials 2003, 24, 2363-2378.

[21] X. Z. Shu, S. Ahmad, Y. Liu, G. D. Prestwich, J. Biomed. Mater. Res., Part A 2006, 79A, 902-912.

[22] T. A. E. Ahmed, M. Griffith, M. Hincke, Tissue Eng. 2007, 13, 1469-1477.

[23] B. Balakrishnan, A. Jayakrishnan, Biomaterials 2005, 26, 3941-3951.

[24] A. Chenite, C. Chaput, D. Wang, C. Combes, M. Buschmann, C. Hoemann, J. Leroux, B. Atkinson, F. Binette, A. Selmani, Biomaterials 2000, 21, 2155-2161.

[25] E. M. Horn, M. Beaumont, X. Z. Shu, A. Harvey, G. D. Prestwich, K. M. Horn, A. R. Gibson, M. C. Preul, A. Panitch, J. Neurosurg.: Spine 2007, 6, 133-140.

[26] M. S. Stosich, J. J. Mao, Plast. Reconstr. Surg. 2007, 119, 71-83; Discussion 84-85.

[27] M. Dadsetan, J. P. Szatkowski, M. J. Yaszemski, L. Lu, Biomacromolecules 2007, 8, 1702-1709.

[28] Y. Qiu, K. Park, Adv. Drug Delivery Rev. 2001, 53, 321-339.

[29] Y. Liu, X. Z. Shu, G. D. Prestwich, Tissue Eng. 2006, 12, 3405-3416.

[30] J. S. Miller, K. R. Stevens, M. T. Yang, B. M. Baker, D.-H. T. Nguyen, D. M. Cohen, E. Toro, A. A. Chen, P. A. Galie, X. Yu, R. Chaturvedi, S. N. Bhatia, C. S. Chen, Nat. Mater. 2012, 11, 768-774.

[31] E. S. Desai, M. Y. Tang, A. E. Ross, R. A. Gemeinhart, Biomed. Mater. 2012, 7, 024108.
[32] Y. Lu, G. Mapili, G. Suhali, S. Chen, K. Roy, J. Biomed. Mater. Res., Part A 2006, 77, 396-405.

[33] K. Arcaute, B. K. Mann, R. B. Wicker, Ann. Biomed. Eng. 2006, 34, 1429-1441.

[34] H. Lin, D. Zhang, P. G. Alexander, G. Yang, J. Tan, A. W.-M. Cheng, R. S. Tuan, Biomaterials 2013, 34, 331-339.

[35] A. Ovsianikov, V. Mironov, J. Stampfl, R. Liska, Exp. Rev. Med. Dev. 2012, 1-21.

[36] P. J. Bártolo, Stereolithography: Materials, Processes and Applications, Springer, New York 2011.

[37] K. Kim, A. Yeatts, D. Dean, J. P. Fisher, Tissue Eng., Part B 2010, 16, 523-539.

[38] J. Stampfl, S. Baudis, C. Heller, R. Liska, A. Neumeister, R. Kling, A. Ostendorf, M. Spitzbart, J. Micromech. Microeng. 2008, 18, 125014.

[39] A. Khademhosseini, R. Langer, Biomaterials 2007, 28, 5087-5092.

[40] F. P. W. Melchels, B. Tonnarelli, A. L. Olivares, I. Martin, D. Lacroix, J. Feijen, D. J. Wendt, D. W. Grijpma, Biomaterials 2011, $32,2878-2884$

[41] L. Moroni, R. Schotel, D. Hamann, J. R. de Wijn, C. A. van Blitterswijk, Adv. Funct. Mater. 2008, 18, 53-60.

[42] M. Kino-Oka, Y. Maeda, T. Yamamoto, K. Sugawara, M. Taya, J. Biosc. Bioeng. 2005, 99, 197-207.

[43] J. J. Stankus, J. Guan, K. Fujimoto, W. R. Wagner, Biomaterials 2006, 27, 735-744.

[44] W. Schuurman, V. Khristov, M. W. Pot, P. R. van Weeren, W. J. A. Dhert, J. Malda, Biofabrication 2011, 3, 021001.

[45] R. A. Rezende, F. de S. Azevedo, F. D. Pereira, V. Kasyanov, X. Wen, J. V. L. de Silva, V. Mironov, J. Nanotechnol. 2012, 1-10.

[46] E. C. Spivey, Z. Z. Khaing, J. B. Shear, C. E. Schmidt, Biomaterials 2012, 33, 4264-4276.

[47] W. Haske, V. W. Chen, J. M. Hales, W. Dong, S. Barlow, S. R. Marder, J. W. Perry, Opt. Express 2007, 15, 3426-3436.

[48] P. Danilevicius, S. Rekstyte, E. Balciunas, A. Kraniauskas, R. Jarasiene, R. Sirmenis, D. Baltriukiene, V. Bukelskiene, R. Gadonas, M. Malinauskas, J. Biomed. Opt. 2012, 17, 081405-081405-7.

[49] W. R. Zipfel, R. M. Williams, W. W. Webb, Nat. Biotechnol. 2003, 21, 1369-1377.

[50] C. W. Hull, A. L. Cohen, S. L. Spence, C. W. Lewis, US Patent 5447822, 1995.

[51] C. W. Hull, US Patent 4575330, 1986.

[52] A. K. O'Brien, N. B. Cramer, C. N. Bowman, J. Polym. Sci., Part A: Polym. Chem. 2006, 44, 2007-2014.

[53] R. P. Sinha, D. P. Häder, Photochem. Photobiol. Sci. 2002, 1 , 225-236.

[54] A. Vogel, V. Venugopalan, Chem. Rev. 2003, 103, 577-644.

[55] G. Leitz, E. Fällman, S. Tuck, O. Axner, Biophys. J. 2002, 82, 2224-2231

[56] N. Shen, D. Datta, C. B. Schaffer, P. LeDuc, D. E. Ingber, E. Mazur, Mech. Chem. Biosyst. 2005, 2, 17-25.

[57] M. W. Tibbitt, A. M. Kloxin, K. U. Dyamenahalli, K. S. Anseth, Soft Matter 2010, 6, 5100-5108.

[58] A. Doraiswamy, C. Jin, R. J. Narayan, P. Mageswaran, P. Mente, R. Modi, R. Auyeung, D. B. Chrisey, A. Ovsianikov, B. Chichkov, Acta Biomater. 2006, 2, 267-275.

[59] L. H. Nguyen, M. Straub, M. Gu, Adv. Funct. Mater. 2005, 15, 209-216.

[60] H. Liao, D. Munoz-Pinto, X. Qu, Y. Hou, M. A. Grunlan, M. S. Hahn, Acta Biomater 2008, 4, 1161-1171.

[61] K. Cicha, Z. Li, K. Stadlmann, A. Ovsianikov, R. Markut-Kohl, R. Liska, J. Stampfl, J. Appl. Phys. 2011, 110, 064911-064911-5.

[62] A. Ovsianikov, S. Schlie, A. Ngezahayo, A. Haverich, B. N. Chichkov, J. Tissue Eng. Regener. Med. 2007, 1, 443-449.

[63] F. Klein, T. Striebel, J. Fischer, Z. Jiang, C. M. Franz, G. von Freymann, M. Wegener, M. Bastmeyer, Adv. Mater. 2010, 22, 868-871.

[64] K. J. Schafer, J. M. Hales, M. Balu, K. D. Belfield, E. W. Van Stryland, D. J. Hagan, J. Photochem. Photobiol., A 2004, 162, 497-502. 
[65] M. Sheik-Bahae, A. A. Said, T.-H. Wei, D. J. Hagan E. W. Van Stryland, IEEE J. Quantum Electron. 1990, 26, 760-769.

[66] P. J. Campagnola, D. M. Delguidice, G. A. Epling, K. D. Hoffacker, A. R. Howell, J. D. Pitts, S. L. Goodman, Macromolecules 2000, 33 1511-1513.

[67] S. Huang, A. A. Heikal, W. W. Webb, Biophys. J. 2002, 82, 2811-2825.

[68] H. Y. Woo, B. Liu, B. Kohler, D. Korystov, A. Mikhailovsky, G. C. Bazan, J. Am. Chem. Soc. 2005, 127, 14721-14729.

[69] T. Weiß, R. Schade, T. Laube, A. Berg, G. Hildebrand, R. Wyrwa, M. Schnabelrauch, K. Liefeith, Adv. Eng. Mater. 2011, 13, B264-B273.

[70] A. Ovsianikov, M. Gruene, M. Pflaum, L. Koch, F. Maiorana, M. Wilhelmi, A. Haverich, B. Chichkov, Biofabrication 2010, 2, 014104.

[71] A. Ovsianikov, M. Malinauskas, S. Schlie, B. N. Chichkov, S. Gittard, R. Narayan, M. Löbler, K. Sternberg, K.-P. Schmitz, A. Haverich, Acta Biomater. 2011, 7, 967-974.

[72] S. J. Jhaveri, J. D. McMullen, R. Sijbesma, L.-S. Tan, W. Zipfel, C. K. Ober, Chem. Mater. 2009, 21, 2003-2006.

[73] A. Ovsianikov, A. Deiwick, S. Van Vlierberghe, M. Pflaum, M. Wilhelmi, P. Dubruel, B. Chichkov, Materials 2011, 4, 288-299.

[74] M. Farsari, G. Filippidis, K. Sambani, T. S. Drakakis, C. Fotakis, J. Photochem. Photobiol., A 2006, 181, 132-135.

[75] J. D. Pitts, P. J. Campagnola, G. A. Epling, S. L. Goodman, Macromolecules 2000, 33, 1514-1523.

[76] S. Basu, V. Rodionov, M. Terasaki, P. J. Campagnola, Opt. Lett. 2005, 30, 159-161

[77] X. Wan, Y. Zhao, J. Xue, F. Wu, X. Fang, J. Photochem. Photobiol., A 2009, 202, 74-79.

[78] S. K. Seidlits, C. E. Schmidt, J. B. Shear, Adv. Funct. Mater. 2009 19, 3543-3551.

[79] E. C. Spivey, E. T. Ritschdorff, J. L. Connell, C. A. McLennon, C. E. Schmidt, J. B. Shear, Adv. Funct. Mater. 2013, 23, 333-339.

[80] J. D. Pitts, A. R. Howell, R. Taboada, I. Banerjee, J. Wang, S. L. Goodman, P. J. Campagnola, Photochem. Photobiol. 2002, 76, 135-144.

[81] Z. Li, M. Siklos, N. Pucher, K. Cicha, A. Ajami, W. Husinsky, A. Rosspeintner, E. Vauthey, G. Gescheidt, J. Stampfl, R. Liska, J. Polym. Sci., Part A: Polym. Chem. 2011, 49, 3688-3699.

[82] G. S. He, J. Zhu, A. Baev, M. Samoć, D. L. Frattarelli, N. Watanabe, A. Facchetti, H. Ågren, T. J. Marks, P. N. Prasad, J. Am. Chem. Soc. 2011, 133, 6675-6680.

[83] M. Rumi, J. E. Ehrlich, A. A. Heikal, J. W. Perry, S. Barlow, Z. Hu, D. McCord-Maughon, T. C. Parker, H. Röckel, S. Thayumanavan S. R. Marder, D. Beljonne, J.-L. Brédas, J. Am. Chem. Soc. 2000 $122,9500-9510$.

[84] K.-S. Lee, R. H. Kim, D.-Y. Yang, S. H. Park, Prog. Polym. Sci. 2008, 33, 631-681.

[85] Y. Liu, X. Dong, J. Sun, C. Zhong, B. Li, X. You, B. Liu, Z. Liu, Analyst 2012, 137, 1837.

[86] A. Hayek, F. Bolze, J.-F. Nicoud, P. L. Baldeck, Y. Mély, Photochem. Photobiol. Sci. 2006, 5, 102-106.

[87] B. H. Cumpston, S. P. Ananthavel, S. Barlow, D. L. Dyer, J. E. Ehrlich, L. L. Erskine, A. A. Heikal, S. M. Kuebler, I.-Y. S. Lee, D. McCord-Maughon, J. Qin, H. Röckel, M. Rumi, X.-L. Wu, S. R. Marder, J. W. Perry, Nature 1999, 398, 51-54.

[88] J. Torgersen, A. Ovsianikov, V. Mironov, N. Pucher, X. Qin, Z. Li, K. Cicha, T. Machacek, R. Liska, V. Jantsch, J. Stampfl, J. Biomed. Opt. 2012, 17, 105008-105008.

[89] Z. Li, N. Pucher, K. Cicha, J. Torgersen, S. C. Ligon, A. Ajami, W. Husinsky, A. Rosspeintner, E. Vauthey, S. Naumov, T. Scherzer, J. Stampfl, R. Liska, Macromolecules 2013, 46, 352-361.

[90] J. A. Burdick, G. D. Prestwich, Adv. Mater. 2011, 23, H41-H56.

[91] T. Weiß, G. Hildebrand, R. Schade, K. Liefeith, Eng. Life Sci. 2009, 9, 384-390.

[92] C. N. LaFratta, J. T. Fourkas, T. Baldacchini, R. A. Farrer, Angew. Chem., Int. Ed. 2007, 46, 6238-6258.
[93] S. J. Bryant, K. S. Anseth, J. Biomed. Mater. Res., Part A 2003, 64A, 70-79.

[94] Q. T. Nguyen, Y. Hwang, A. C. Chen, S. Varghese, R. L. Sah, Biomaterials 2012, 33, 6682-6690.

[95] A. Berg, R. Wyrwa, J. Weisser, T. Weiss, R. Schade, G. Hildebrand, K. Liefeith, B. Schneider, R. Ellinger, M. Schnabelrauch, Adv. Eng. Mater. 2011, 13, B274-B284.

[96] J. C. Hoffmann, J. L. West, Soft Matter 2010, 6, 5056-5063.

[97] E. Santos, G. Orive, R. M. Hérnandez, J. L. Pedranz, in On biomimetics (Ed:L. Pramatarova), InTech, Rijeka, Croatia, 2011.

[98] S.-H. Lee, J. J. Moon, J. L. West, Biomaterials 2008, 29, 2962-2968.

[99] J. E. Leslie-Barbick, C. Shen, C. Chen, J. L. West, Tissue Eng., Part A 2011, 17, 221-229.

[100] A. M. Kloxin, A. M. Kasko, C. N. Salinas, K. S. Anseth, Science 2009, 324, 59-63.

[101] C. A. DeForest, K. S. Anseth, Nat. Chem. 2011, 3, 925-931.

[102] C. A. DeForest, K. S. Anseth, Angew. Chem. 2012, 124, 1852-1855.

[103] A. F. Lasagni, D. Yuan, P. Shao, S. Das, Adv. Eng. Mater. 2009, 11, B20-B24.

[104] S. D. Gittard, A. Ovsianikov, H. Akar, B. Chichkov N. A. Monteiro-Riviere, S. Stafslien, B. Chisholm, C.-C. Shin C.-M. Shih, S.-J. Lin, Y.-Y. Su, R. J. Narayan, Adv. Eng. Mater. 2010, 12, B77-B82.

[105] A. Ovsianikov, A. Deiwick, S. Van Vlierberghe, P. Dubruel, L. Möller, G. Dräger, B. N. Chichkov, Biomacromolecules 2011, 12, 851-858.

[106] E. T. Ritschdorff, R. Nielson, J. B. Shear, Lab Chip 2012, 12, 867-871.

[107] R. Allen, R. Nielson, D. D. Wise, J. B. Shear, Anal. Chem. 2005, 77 5089-5095.

[108] B. Kaehr, J. B. Shear, Proc. Natl. Acad. Sci. USA 2008, 105, 8850-8854

[109] J. C. Harper, S. M. Brozik, C. J. Brinker, B. Kaehr, Anal. Chem. 2012 84, 8985-8989.

[110] B. Kaehr, R. Allen, D. J. Javier, J. Currie, J. B. Shear, Proc. Nat. Acad. Sci. USA 2004, 101, 16104-16108.

[111] K. Kuetemeyer, G. Kensah, M. Heidrich, H. Meyer, U. Martin, I. Gruh, A. Heisterkamp, Opt. Express 2011, 19, 15996-16007.

[112] L. P. Cunningham, M. P. Veilleux, P. J. Campagnola, Opt. Express 2006, 14, 8613-8621.

[113] S. Basu, P. J. Campagnola, J. Biomed. Mater. Res., Part A 2004, 71A 359-368.

[114] C. Heller, M. Schwentenwein, G. Russmueller, F. Varga, J. Stampfl, R. Liska, J. Polym. Sci., Part A: Polym. Chem. 2009, 47, 6941-6954.

[115] B. Husár, R. Liska, Chem. Soc. Rev. 2012, 41, 2395-2405.

[116] B. V. Slaughter, S. S. Khurshid, O. Z. Fisher, A. Khademhosseini, N. A. Peppas, Adv. Mater. 2009, 21, 3307-3329.

[117] A. Mautner, X. Qin, H. Wutzel, S. C. Ligon, B. Kapeller, D. Moser G. Russmueller, J. Stampfl, R. Liska, J. Polym. Sci., Part A: Polym. Chem. 2013, 51, 203-212.

[118] J. W. Hawkins, A. Dugaiczyk, Gene 1982, 19, 55-58.

[119] D. A. Fancy, T. Kodadek, Proc. Nat. Acad. Sci. USA 1999, 96, 6020-6024.

[120] S. Basu, L. P. Cunningham, G. D. Pins, K. A. Bush, R. Taboada A. R. Howell, J. Wang, P. J. Campagnola, Biomacromolecules 2005 6, 1465-1474

[121] C. Y. Khripin, C. J. Brinker, B. Kaehr, Soft Matter 2010, 6, 2842-2848.

[122] A. I. Van Den Bulcke, B. Bogdanov, N. De Rooze, E. H. Schacht, M. Cornelissen, H. Berghmans, Biomacromolecules 2000, 1, 31-38.

[123] M. C. Murphy, N. K. Howell, J. Sci. Food Agric. 1991, 55, 489-492.

[124] G. Kumi, C. O. Yanez, K. D. Belfield, J. T. Fourkas, Lab Chip 2010, 10, 1057

[125] M. Malinauskas, V. Purlys, M. Rutkauskas, R. Gadonas, in Proc. SPIE, San Jose, California, USA, 2009, S. 72040C-72040C

[126] A. Ovsianikov, Z. Li, J. Torgersen, J. Stampfl, R. Liska, Adv. Funct. Mater. 2012, 22, 3429-3433. 